\title{
Oxidative stress in hoof laminar tissue of horses with lethal gastrointestinal diseases
}

\author{
Luciane Maria Laskoski $^{\mathrm{a}, *}$, Rosangela Locatelli Dittrich ${ }^{\mathrm{a}}$, Carlos Augusto Araújo Valadão ${ }^{\mathrm{b}}$, \\ Juliana Sperotto Brum ${ }^{\mathrm{a}}$, Yara Brandão ${ }^{\mathrm{c}}$, Harald Fernando Vicente Brito ${ }^{\mathrm{a}}$, \\ Renato Silva de Sousa ${ }^{d}$ \\ a Graduate School in Veterinary Sciences, Federal University of Paraná (Curitiba campus), Rua dos Funcionários, 1540, Curitiba, Paraná 80035-050, Brazil \\ ${ }^{\mathrm{b}}$ Graduate School in Veterinary Surgery, São Paulo State University Júlio de Mesquita Filho - UNESP (Jaboticabal campus), Via de Acesso Professor Paulo \\ Donato Castellane, s/n, Jaboticabal, São Paulo 14884-900, Brazil \\ ${ }^{\mathrm{c}}$ Graduate School in Microbiology, Parasitology and Patology, Federal University of Paraná (Curitiba campus), Avenida Coronel Francisco H. dos Santos, s/n, \\ Curitiba, Paraná 81530-900, Brazil \\ d Department of Veterinary Medicine, Federal University of Paraná (Curitiba campus), Rua dos Funcionários, 1540, Curitiba, Paraná 80035-050, Brazil
}

\section{A R T I C L E I N F O}

\section{Article history:}

Received 13 October 2015

Received in revised form

16 December 2015

Accepted 7 February 2016

\section{Keywords:}

Laminitis

Equine

Nitrotyrosine

Superoxide dismutase

Immunohistochemistry

\begin{abstract}
A B S T R A C T
Tissue damage caused by oxidative stress is involved in the pathogenesis of several diseases in animals and man, and is believed to play a role in the development of laminitis in horses. The aim of this study was to investigate the oxidative stress associated with laminar lesions in horses with lethal gastrointestinal disorders. Laminar tissue samples of the hoof of 30 horses were used. Tissue samples were divided as follows: six healthy horses (control group-CG), and 24 horses that died after complications of gastrointestinal diseases (group suffering from gastrointestinal disorders-GDG). Superoxide dismutase (SOD2) and nitrotyrosine immunostaining and the severity of laminar lesions were evaluated. Presence of laminar lesions and immunostaining for nitrotyrosine and SOD2 were only evident in horses from the GDG group. Thus, oxidative stress may play a role in the pathogenesis of laminar lesions secondary to gastrointestinal disorders.
\end{abstract}

(C) 2016 Elsevier B.V. All rights reserved

\section{Introduction}

Laminitis is a serious condition, commonly seen in horses after severe episodes of gastrointestinal diseases (Parsons et al., 2007). Lesions occurs in the hoof laminar tissue located between the hoof wall and the distal phalanx, responsible for joining and supporting these structures (Pollitt, 1996; Karikoski et al., 2014).

The study of laminitis is usually carried out experimentally induced inflammatory models such as by BWE administration or carbohydrate-overload (Loftus et al., 2006; Faleiros et al., 2009;

Abbreviations: BM, basement membrane; BC, basal cells; BWE, black walnut extract; CG, control group; CS, clinical signs (horse with clinical signs of laminitis before death); DNA, deoxyribonucleic acid; GDG, gastrointestinal disorders group; PEL, primary epidermal laminae; SDL, secondary dermal laminae; SEL, secondary epidermal laminae; SOD, superoxide dismutase; TNF- $\alpha$, tumor necrosis factor- $\alpha$.

* Corresponding author.

E-mail addresses: luci.laskoski@gmail.com (L.M. Laskoski), roslocdi@ufpr.br (R.L. Dittrich), valadao@fcav.unesp.br (C.A.A. Valadão), julianasbrum@yahoo.com.br (J.S. Brum),yara_brandao@hotmail.com (Y. Brandão), haraldvet@yahoo.com.br (H.F.V. Brito), renatosousa@ufpr.br (R.S. de Sousa).
Lima et al., 2013; Steelman et al., 2014) or inducing endocrinopathic laminitis such as by insulin administration (de Laat et al., 2012). However, the presence of morphological lesions in the hoof laminar tissue can also be observed by inducing gastrointestinal disorders (Laskoski et al., 2010) and in naturally occurring colic syndrome even without clinical signs of laminitis (Laskoski et al., 2015).

Distinct theories to explain laminitis secondary to inflammatory diseases exist. One of the theories proposed to explain the physiopathology laminitis suggests the occurrence of laminar ischemia secondary to vasoconstriction or due to vascular obstruction by a thrombus (Weiss et al., 1994; Noschka et al., 2009a). Degradation of basement membrane-type collagen by metalloproteinases also was identified as a potential cause for this injury (Pollitt, 1996). Another theory is the metabolic laminitis, which has many similarities with the disease induced by inflammatory models, such as insulin resistance and resulting hyperglycemia during the prodromic phase of laminitis (Toth et al., 2009). Recently, associations between systemic inflammation and laminitis have been observed (Loftus et al., 2007; Faleiros et al., 2009). However, theories for the development of laminitis and consequent findings seem to vary 
according to the type of experimentally-induced laminitis model investigated.

Oxidative stress is associated with the pathogenesis of many diseases, causing cellular injury by reaction of free radicals with cellular proteins, lipids and DNA (Berg et al., 2004). Peroxynitrite is derived from the reaction of nitric oxide with superoxide anions (Carreras et al., 1994). It is a potent bactericidal and parasiticidal agent, whose products can lead to the formation of substances that cause oxidative damage (Zhu et al., 1992 Alvarez et al., 2004), inducing cytotoxicity by oxidation of tryptophan and cysteine, tyrosine nitration, formation of dityrosine, and protein fragmentation (Ischiropoulos and Al-Mehdi, 1995). While superoxide anions and nitric oxide are generated almost exclusively by endothelial cells, peroxynitrite can be generated by the reaction of these two substances in the extracellular environment (Frei et al., 1988; Halliwell and Gutteridge, 1990). Nitrotyrosine is a product from tyrosine residues reacting with peroxynitrite, and has been used as a marker of oxidative stress (Ischiropoulos and Al-Mehdi, 1995).

Oxidative stress occurs when the amount of substances responsible for oxidative damage exceeds the capacity of neutralization by the antioxidant system (Macdonald et al., 2003). The SOD is an important cellular antioxidant enzyme, which is also present in the extracellular milieu, plays an important role in preventing the decomposition of nitric oxide, and promotes vasodilatation, besides catalyzing the decomposition of superoxide, leading to the protection of the endothelium and other tissues by inhibiting the subsequent formation of peroxynitrite (Beckman et al., 1990).

Some authors have suggested laminar tissue lesions caused by oxidative stress. Yin et al. (2009) observed an increase of a lipid aldehyde, which causes lipid peroxidation during the developmental phase of laminitis induced by administration of BWE. Antioxidant substances such as catalase and xanthine oxidase are present in the hoof laminar tissue of healthy horses, but SOD is not found in healthy animals (Loftus et al., 2006).

The aim of this study was to evaluate the immunolocalization of SOD and nitrotyrosine in the hoof laminar tissue of healthy horses and horses suffering from serious colic syndrome, and the association of these findings with the development of laminar injury.

\section{Materials and methods}

\subsection{Ethics committee}

The experiment was approved by the Research Ethics Committee of the Federal University of Parana (Protocol 038/2012).

\subsection{Animals}

Samples of hoof laminar tissue from the four limbs were collected immediately after the death of thirty male and female horses from different breeds, weighing between $280-560 \mathrm{~kg}$. The animals were divided in two experimental groups: Control group (CG), with six horses from a commercial slaughterhouse (aged 6-10 years), and gastrointestinal disorders group (GDG), with 24 horses that died or were submitted to euthanasia after complications caused by natural gastrointestinal complications (aged $2-15$ years).

\subsection{Experimental design}

Control Group (CG): with six crossbreed horses, considered to be healthy by the local inspection service of a commercial slaughterhouse (Slaughterhouse and refrigerator Pomar SA, Araguari-MG, Brazil).

Gastrointestinal Disorders Group (GDG): with 24 horses suffering from naturally occurring gastrointestinal lethal diseases, treated at Veterinary Hospitals of Higher Education Institutions. The causes of gastrointestinal disorders were proximal duodenal-jejunitis $(n=1)$, grain overload $(n=2)$, enterolithiasis $(n=4)$, intestinal impactation $(n=6)$ and colon displacement/twisted bowel $(n=11)$, which caused death or led to the indication of euthanasia due to intestinal ischemia and necrosis. All horses were evaluated, during disease evolution period, for the presence of lameness associated to laminitis.

\subsection{Morphology of the hoof laminar tissue}

After the death of the animals, hoof laminar tissue of the four limbs was collected with a scalpel blade and forceps after crosssectioning the hoof wall (Pollitt, 1996). Samples were fixed in 10\% buffered formalin for $48 \mathrm{~h}$, and routinely processed and stained with hematoxylin and eosin (HE) and periodic acid-Schiff (PAS) for histologic evaluation. Light microscopy was performed by three observers, following the method described by Pollitt (1996) with adaptation, and the severity of laminar lesions were graded as 0,1 , 2 and 3 (Table 1 ).

\subsection{Immunohistochemistry for nitrotyrosine and SOD2}

Nitrotyrosine and SOD2 in hoof laminar tissue were investigated in horses of both CG and GAG groups using immunohistochemistry, Paraffin-embedded tissue sections $(5 \mu \mathrm{m})$ placed on positively charged slides were deparaffinized and antigen retrieval was performed in sodium citrate using a slow cooker for $30 \mathrm{~min}$ $\left(92-95^{\circ} \mathrm{C} / 197-203^{\circ} \mathrm{F}\right)$. A commercial kit was used to block proteins (DPB-125, Spring Bioscience. Pleasanton, CA, EUA), and endogenous peroxidase (DHP-125, Spring Bioscience. Pleasanton, CA, EUA). Mouse anti-nitrotyrosine (AB 61392, ABCAM, San Francisco, USA) antibody was diluted 1:6000, and rabbit anti-SOD2 (AB 13534, ABCAM, San Francisco, USA) antibody was diluted $1: 4000$. Both antibodies were incubated for $60 \mathrm{~min}$ at room temperature, following incubation with universal immunoperoxidase polymer (Nichi-414152-F, NICHIREI BIOSCIENCE INC, Tokyo, Japan) for $30 \mathrm{~min}$. The DAB reaction was performed for four minutes and counterstained with Harris hematoxylin for $30 \mathrm{~s}$, dehydrated with ethanol, cleared with xylene and mount with a resinous medium. Slides were evaluated by three independent observers.

Evaluation of nitrotyrosine and SOD2 staining of hoof laminar tissue was graded according to the immunostaining intensity observed in GAG horses (Tables 2 and 3).

\subsection{Statistical methods}

The Kruskal-Wallis test was used to compare grades of laminar lesions and scores of nitrotyrosine and SOD2 between the groups CG and GDG. Additionally, the Spearman correlation test was used to determine correlation between the grades of laminar lesions and scores of nitrotyrosine and SOD2 immunostaining. In all tests $P<0.05$ was considered significant.

\section{Results}

Laminar lesions and immunostaining for nitrotyrosine and SOD2 were not detected in horses of the CG. All laminar lesion grades (Fig. 1) and all scores of nitrotyrosine (Fig. 2) and SOD2 (Fig. 3) immunostaining were observed in horses from the GDG, with medians higher than the CG (Table 4).

One horse from the GDG developed clinical signs of laminitis, such as increase of digital pulse, lameness and hoof tester positivity, Obel grade IV lameness and forelimb pain. Colic signs were caused by impaction of the transverse colon, treated surgically. In the postoperative period, this horse showed serious lameness and 
Table 1

Morphological characteristics of laminar lesions grades observed in GDG horses (Laskoski et al., 2015).

\begin{tabular}{|c|c|}
\hline Grades & Morphological characteristics \\
\hline 0 & $\begin{array}{l}\text { Normal morphology of interdigitations between secondary epidermal laminae (SEL) and secondary dermal laminae } \\
\text { (SDL) with contour delimited of basement membrane (BM) and elongated nuclei of basal cells }\end{array}$ \\
\hline 1 & SEL lengthening, primary epidermal laminae (PEL) undulations and basal cells (BC) with round-shape nuclei \\
\hline 2 & $\begin{array}{l}\text { There was loss of BM in some segments and its contour was wavy and undulating, with lesions more pronounced in } \\
\text { the SEL and PEL }\end{array}$ \\
\hline 3 & $\begin{array}{l}\text { Destruction of interdigitations and morphology of epidermal and dermal laminae, especially in the base of the PEL, } \\
\text { with increased distance of keratinizes axis of PEL and BM }\end{array}$ \\
\hline
\end{tabular}

Table 2

Scores of immunostaining for nitrotyrosine in hoof laminar tissue of GDG horses.

\begin{tabular}{|c|c|}
\hline Scores & Nitrotyrosine immunostaining \\
\hline 0 & Absence of immunostaining in all laminar sections \\
\hline 1 & Immunostaining in leukocytes intravascular and endothelial cells, localized in dermal laminae \\
\hline 2 & Immunostaining in interdigitations formed between dermal and epidermal laminae, and nitrotyrosine residues in tissue \\
\hline 3 & Disseminated immunostaining, with impossible cell counting, between interdigitations in dermal and epidermal laminae (with nitrotyrosine residues) \\
\hline
\end{tabular}

Table 3

Scores of immunostaining for SOD2 in hoof laminar tissue of GDG horses.

\begin{tabular}{|c|c|}
\hline Scores & Immunostaining for SOD2 \\
\hline 0 (absente) & Absence of immunostaining in all laminar section \\
\hline 1 (weak) & Immunostaining of weak intensity, observed in extremity of epidermal laminae \\
\hline 2 (moderate) & Immunostaining of moderate intensity, observed in extremity of epidermal laminae \\
\hline 3 (strong) & Immunostaining of strong intensity, observed in epidermal laminae in all laminar sections \\
\hline
\end{tabular}

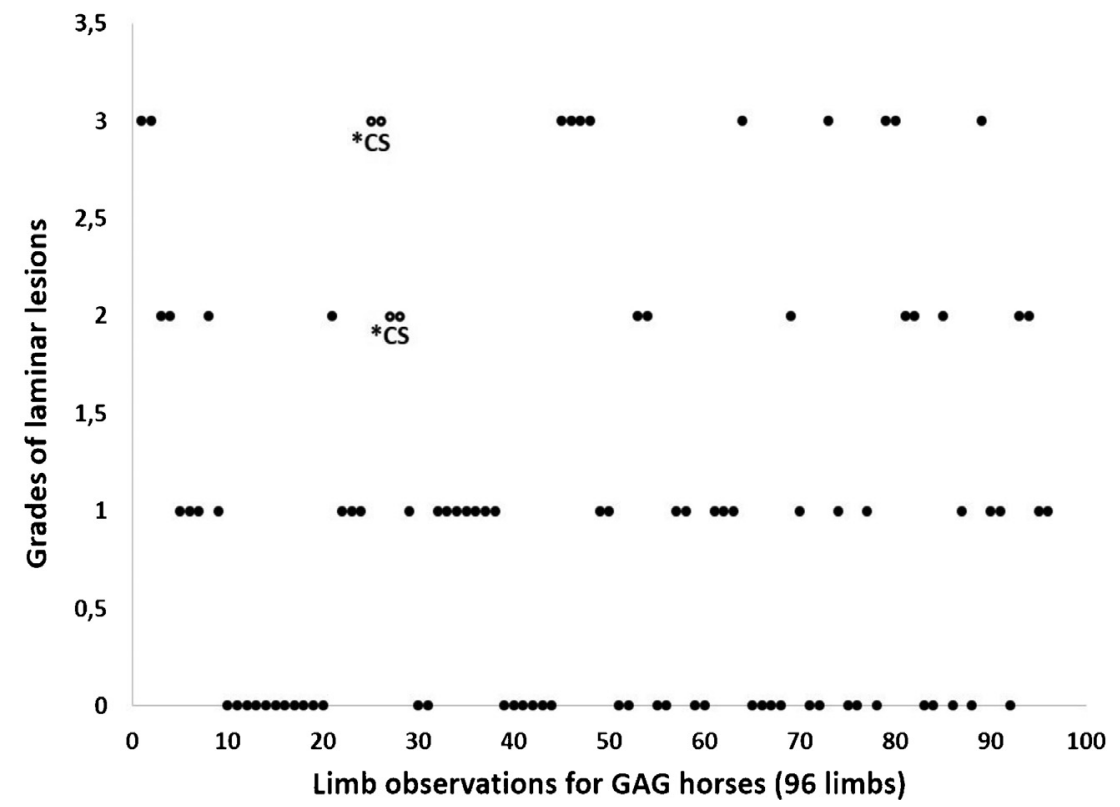

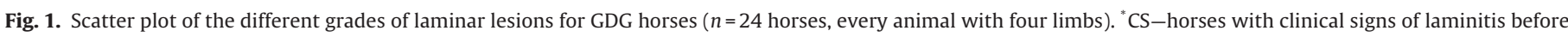
death (unfilled dots).

Table 4

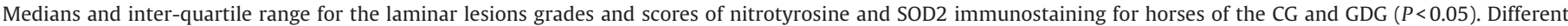
letters in the same column indicate statistical difference.

\begin{tabular}{|c|c|c|c|}
\hline & Grades of laminar lesion & Scores of nitrotyrosine immunostaining & Scores of SOD2 immunostaining \\
\hline CG & $0(0-0) a$ & $0(0-0) a$ & $0(0-0) a$ \\
\hline GDG & $1(1-2) b$ & $0(0-1) a$ & $1(0-1) b$ \\
\hline
\end{tabular}

received treatment for laminitis. After one week, the previously affected intestinal segment developed necrosis resulting in death of the horse. This animal was evaluated as a grade 3 laminar lesions in forelimbs and grade 2 in hindlimbs; score 3 nitrotyrosine immunos- taining in all limbs; score 1 SOD2 immunostaing in forelimbs and left hindlimb and score 0 in right hindlimb (Figs. 1-3).

The main morphological changes observed in the hoof laminar tissue of the animals were round-shape nuclei of basal cells (BC), secondary epidermal laminae (SEL) lengthening, primary 


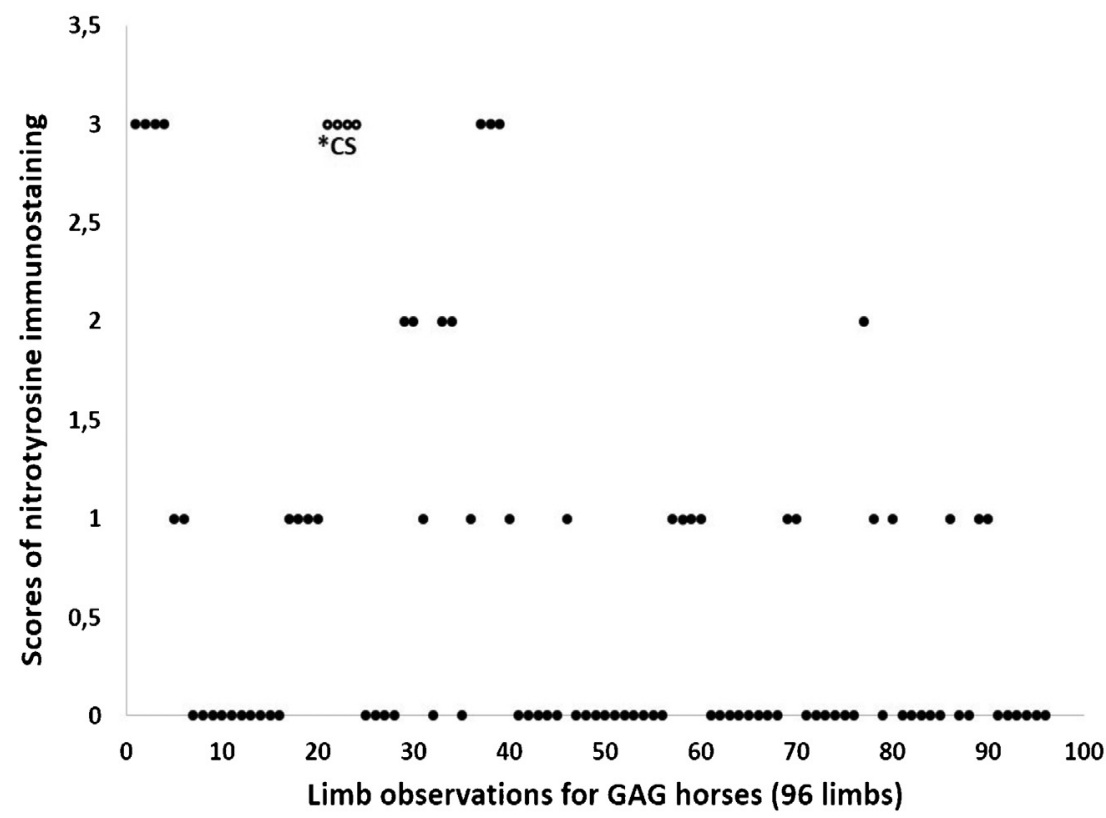

Fig. 2. Scatter plot of the different scores of nitrotyrosine immunostaining for GDG horses ( $n=24$ horses, every animal with four limbs). " $C S-$ horse with clinical signs of laminitis before death (unfilled dots).

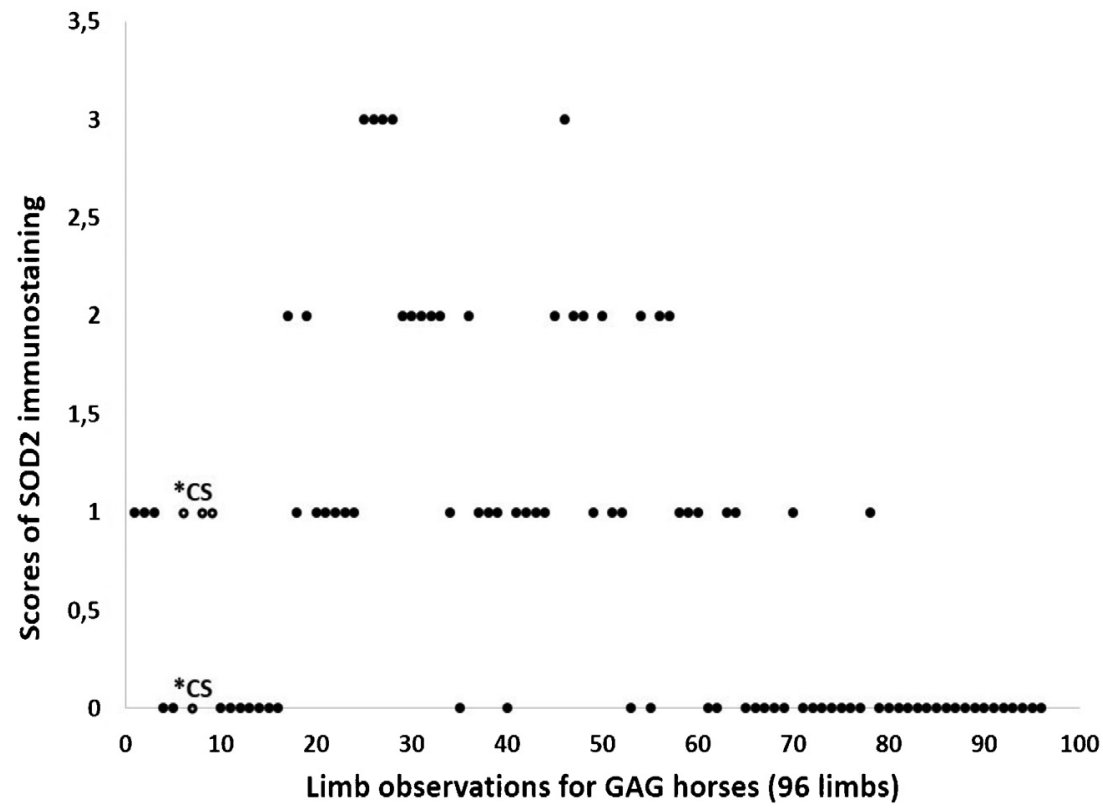

Fig. 3. Scatter plot of the different scores of SOD2 immunostaining for GDG horses ( $n=24$ horses, every animal with four limbs). ${ }^{*} \mathrm{CS}-$ horse with clinical signs of laminitis before death (unfilled dots).

epidermal laminae (PEL) undulations, absence of basement membrane (BM) in some segments and its wavy contour and undulation. Only five horses showed lesions of grade 3 . Of these five horses, only one had clinical signs of laminitis.

Nitrotyrosine immunostaining was observed in dermal laminae, in cytoplasm and in the nucleus of endothelial cells and leukocytes and as nitrotyrosine residues into blood vessels or in tissue, but only in horses from the GDG (Fig. 4). Of the five horses with grade 3 laminar lesions, two did not show nitrotyrosine immunostaining, two showed score 1 of nitrotyrosine immunostaining and the horse that developed clinical laminitis before death had score 3 of nitrotyrosine immunostaining in all limbs.

The SOD2 immunostaining was detected in basal cell cytoplasm, and epidermal laminae (Fig. 5). The most intense SOD2 immunos- taining (score 3) was observed only in limbs with laminar lesions of grade 3 . Weak and moderate immunostaining was observed even in limbs without laminar lesions, but only in GDG horses.

No correlation was observed between grades of laminar lesions and scores of nitrotyrosine and SOD 2 immunostaining.

\section{Discussion}

The results of this study contribute to the accumulated knowledge about laminitis in horses suffering from severe gastrointestinal diseases. Presence of nitrotyrosine, which was observed only in horses suffering from colic syndrome and not in the healthy ones, is associated with oxidative stress, since it is a product of 

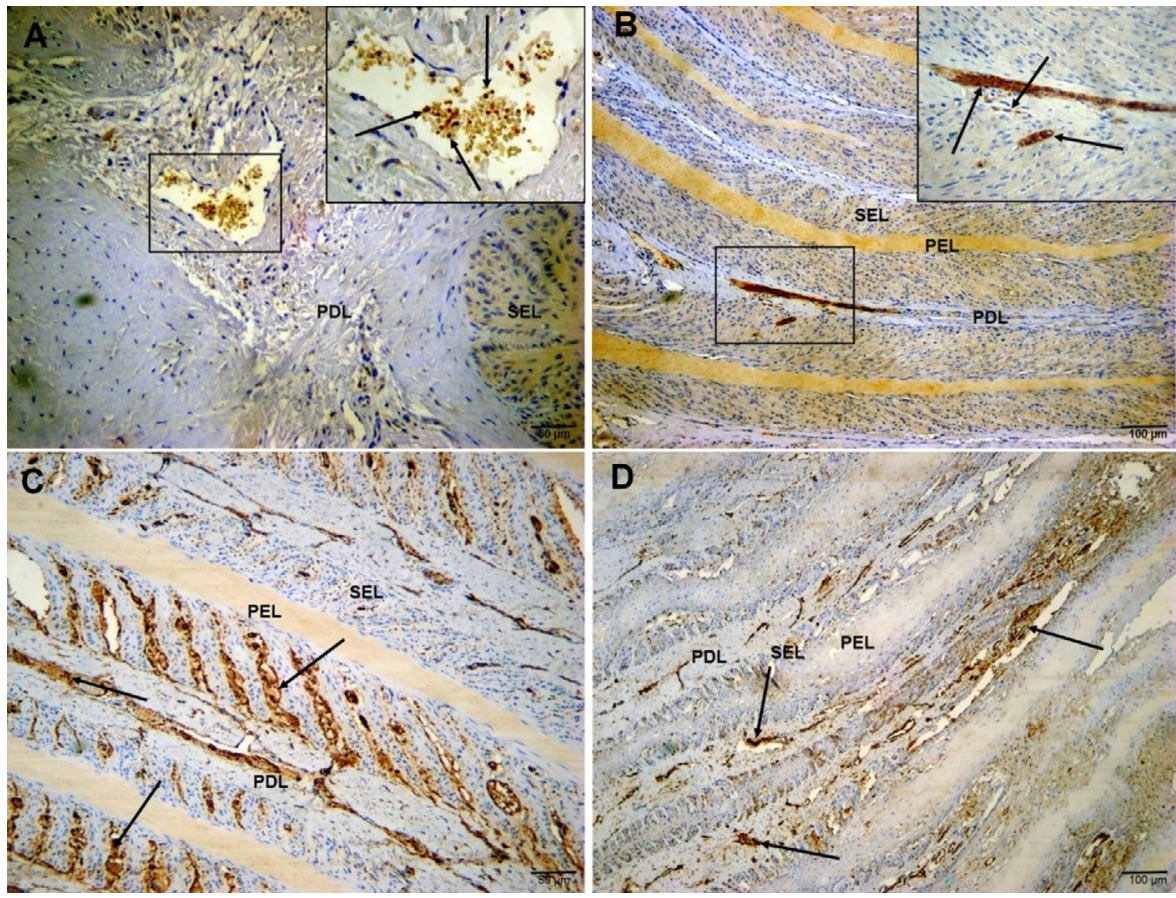

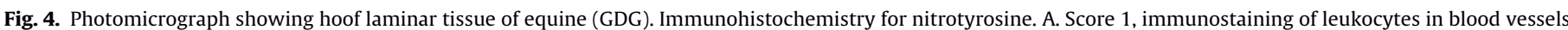

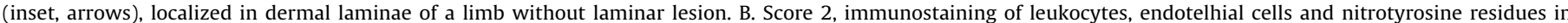

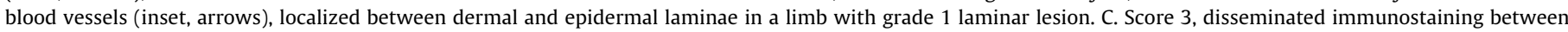

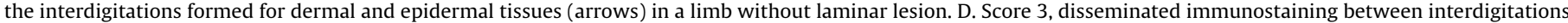
(arrows) in a limb with intense laminar lesions of grade 3. PEL-primary epidermal laminae; SEL-secondary epidermal laminae; SDL-secondary dermal laminae.
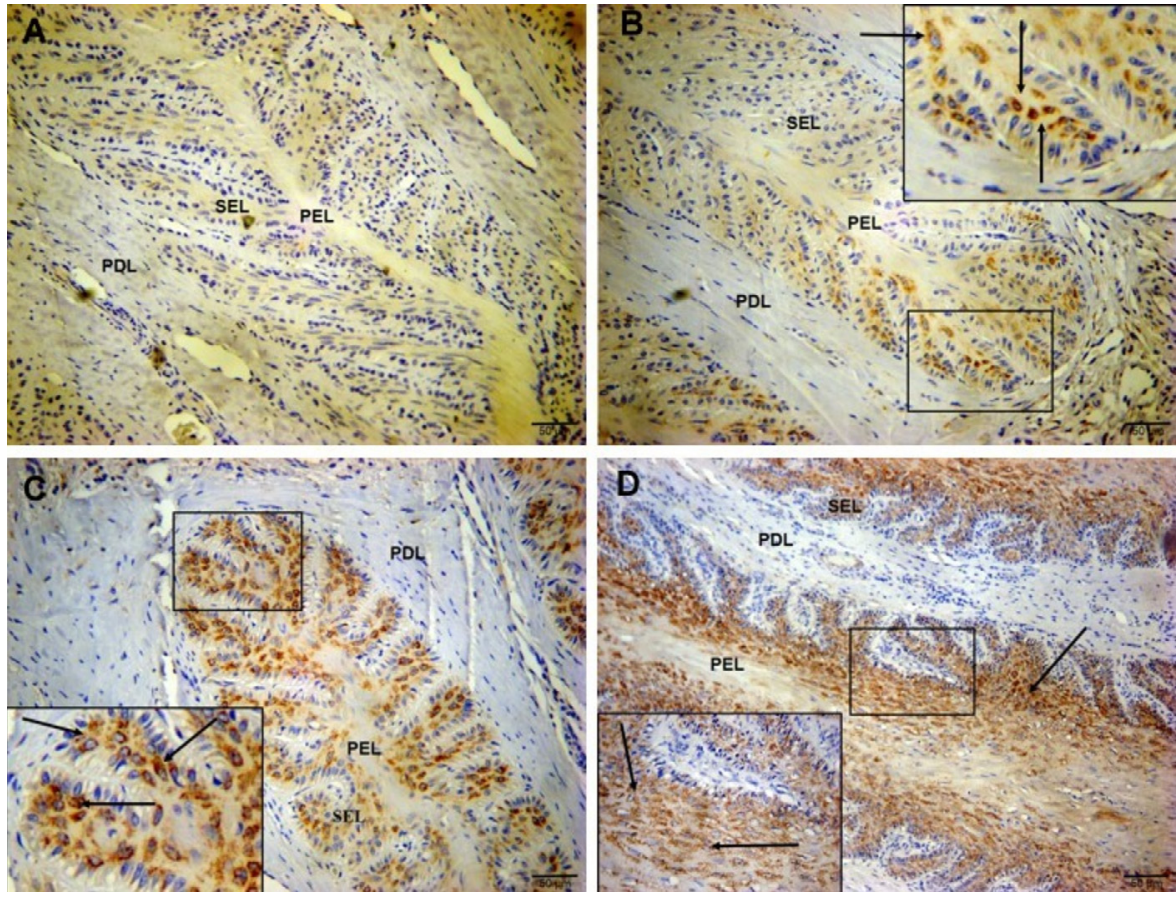

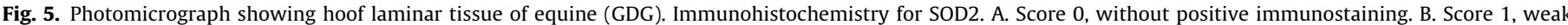

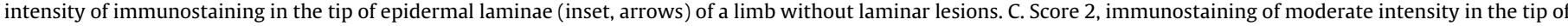

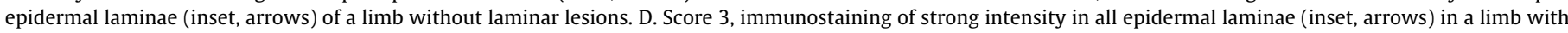
intense laminar lesions of grade 3. PEL-primary epidermal laminae; SEL-secondary epidermal laminae; SDL-secondary dermal laminae.

peroxynitrite (Ischiropoulos and Al-Mehdi, 1995). Peroxynitrite, which is a reactive secondary species is related to pathological processes, especially because it irreversibly binds to proteins (Szabó et al., 2007; Weidinger and Kozlov, 2015).
There was no correlation between staining for nitrotyrosine and laminar injury. However, it is known that peroxynitrite leads to tissue degeneration, and thus is formed prior to the development of the lesion (Ischiropoulos and Al-Mehdi, 1995; Weidinger and Kozlov, 2015; Szabó et al., 2007), which may explain the results 
found in animals with grade 3 laminar lesions. These horses even suffering from severe laminar lesion showed weak staining for nitrotyrosine, indicating that oxidative stress may have occurred prior to the injury. Strong immunostaining for nitrotyrosine was observed in only one of the five horses suffering from grade 3 laminar injuries. However, this animal developed postoperative laminitis, with subsequent worsening of the condition, leading to necrosis of the intestinal loop and death. In this case, we suggest that new oxidant response may have occurred due to the worsening of intestinal injury, generating increased laminar peroxynitrite that could result in loss of hoof capsule if the animal had survived.

Oxidative stress has been investigated as a possible cause of laminar injury by some researchers. de Laat et al. (2012) observed an increased concentration of advanced glycation end products (AGEs) in horses with insulin-induced laminitis. These substances, when bounded to their receptors, cause the release of inflammatory mediators and induce oxidative stress. Yin et al. (2009) demonstrated that lipid peroxidation occurs during the development and acute phases of laminitis induced by BWE. Burns et al. (2011) did not find evidence of this lipid peroxidation with the same substance-4HNE (4-hydroxynonenal) in carbohydrateinduced laminitis. In our study, nitrotyrosine immunostaining was observed in leukocytes and dermal endothelial cells, corroborating the results obtained by Burns et al. (2011). In both studies, staining was widespread in the epidermal tissue in some horses, and so, this staining was not considered as positive. Unlike the results obtained by Burns et al. (2011), healthy animals did not show positive staining for nitrotyrosine, only animals from the GDG.

SOD2 staining was found only in horses with gastrointestinal disorders, with or without laminar injury, and it was detected in the epidermal laminae, as previously detected in the skin of human beings (Kim, 2013). SOD enzyme is an important cellular antioxidant also present in the extracellular milieu. It prevents the decomposition of nitric oxide and catalyzes the decomposition of superoxide anions, leading to protection of the endothelium and other tissues due to the reduced peroxynitrite formation (Beckman et al., 1990). However, the SOD has no action on the already formed peroxynitrite (Weidinger and Kozlov, 2015). SOD2 was not found in healthy horses in this study, corroborating the findings of Loftus et al. (2006). The absence of this antioxidant probably contributes to the injury caused by oxidative stress, not only by peroxynitrite, but also by other reactive oxygen and nitrogen species. SOD2 staining in horses with gastrointestinal disorders was not correlated with the development of laminar lesions, since some of the horses without lesions from the GDG showed staining for SOD2. Presence of SOD2 only was observed in horses from the GDG probably indicating that the laminar tissue produces the enzyme after the primary stimulus leading to the development of laminar lesions as reported by Noschka et al. (2009b), which demonstrated that there is an increase in the amount of laminar SOD in horses suffering from grade 1 OBEL after BWE-induced laminitis. Only horses from the GDG with serious laminar lesions showed a strong immunostaining for SOD (score 3).

Considering that this study was conducted in animals suffering from naturally occurring gastrointestinal disorders, it was not possible to standardize the type, course and severity of disease, with the injuries and immunostaining performed. Steelman et al. (2014) conducting a laminitis study in horses with clinical cases of colic syndrome also did not consider these variables; they only considered that the horses were at risk of developing sepsis due to gastrointestinal disease. There is a close association between gastrointestinal diseases and the development of sepsis/SIRS in horse (Faleiros et al., 2008; Moore and Vandenplas, 2014). The examination for inflammatory status was not performed in our study, but according to Kyaw et al. (2008), there is an increase of the systemic concentration inflammatory mediators such as the TNF- $\alpha$ in horses with lethal gastrointestinal disorders. Thus, as the animals died from complications of intestinal diseases it is suggested that they developed SIRS of different severity levels. There is an increase in oxidative stress in sepsis/SIRS, triggering an increase of primary reactive species such as nitric oxide, and secondary ones like peroxynitrite and including SOD antioxidant (Cuzzocrea et al., 2006; Constantino et al., 2014), probably stimulated by inflammatory mediators such as TNF- $\alpha$, which induces tissue injury (Beckman et al., 1990; Seija et al., 2012; Pei et al., 2015). Thus, since the animals of this study were suffering from severe gastrointestinal diseases, it is suggested that the activation and recruitment of reactive oxygen and nitrogen species may have occurred as a response to sepsis.

In conclusion, it is suggested that oxidative stress plays a role in the development of laminar injury in horses suffering from severe gastrointestinal disorders, with the participation of peroxynitrite as the reactive nitrogen species and increase of SOD2 antioxidant. Other oxidative substances not studied can also be associated with this process, especially due to the reduction of SOD2 in laminar tissue in healthy horses.

\section{Conflicts of interest}

None.

\section{References}

Alvarez, M.N., Piacenza, L., Irigo, F., Peluffo, G., Rafael Radi, R., 2004 Macrophage-derived peroxynitrite diffusion and toxicity to Trypanosoma cruzi. Arch. Biochem. Biophys. 432, 222-232.

Beckman, J.S., Beckman, T.W., Chen, J., Marshall, P.A., Freeman, B.A., 1990. Apparent hydroxyl radical production by peroxynitrite: implications for endothelial injury from nitric oxide and superoxide. Proc. Natl. Acad. Sci. U. S. A. 87 $1620--1624$.

Berg, K., Wiseth, R., Bjerve, K., Brurok, H., Gunnes, S., Skarra, S., Jynge, P., Basu, S., 2004. Oxidative stress and myocardial damage during elective percutaneous coronary interventions and coronary angiography. A comparison of blood-borne isoprostane and troponin release. Free Radic. Res. 38, 517-525.

Burns, T.A., Westerman, T., Nuovo, G.J., Watts, M.R., Pettigrew, A., Yin, C., Belknap, J.K., 2011. Role of oxidative tissue injury in the pathophysiology of experimentally induced equine laminitis: a comparison of 2 models. J. Vet. Intern. Med. 25, 540-548.

Carreras, M.C., Pargament, G.A., Catz, S.D., Poderoso, J.J., Boveris, A., 1994. Kinetics of nitric oxide and hydrogen peroxide production and formation of peroxynitrite during the respiratory burst of human neutrophils. FEBS Lett. 341, 65-68.

Constantino, L., Gonçalves, R.C., Giombelli, V.R., Tomasi, C.D., Vuolo, F., Kist, L.W., de Oliveira, G.M., Pasquali, M.A., Bogo, M.R., Mauad, T., Horn Jr., A., Melo, K.V., Fernandes, C., Moreira, J.C., Ritter, C., Dal-Pizzol, F., 2014. Regulation of lung oxidative damage by endogenous superoxide dismutase in sepsis. Intensive Care Med. Exp. 1, 1-11.

Cuzzocrea, S., Mazzon, E., Paola, R., Esposito, E., Macarthur, H., Matuschak, G.M., Salvemini, D., 2006. A role for nitric oxide-mediated peroxynitrite formation in a model of endotoxin-induced shock. J. Pharmacol. Exp. Ther. 319, 73-81.

de Laat, M.A., Kyaw-Tanner, M.T., Sillence, M.N., McGowan, C.M., Pollitt, C.C., 2012. Advanced glycation end products in horses with insulin-induced laminitis. Vet. Immumol. Immunopathol. 145, 395-401.

Faleiros, R.R., Macoris, D.G., Alves, G.E.S., Souza, D.G., Teixeira, M.M., Moore, R.M. 2008. Local and remote lesions in horses subjected to small colon distension and decompression. Can. J. Vet. Res. 72, 68-76.

Faleiros, R.R., Nuovo, G.G., Belknap, J.K., 2009. Calprotectin in myeloid and epithelial cells of laminae from horses with black walnut extract-induced laminitis. J. Vet. Intern. Med. 23, 174-181.

Frei, B., Stocker, R., Ames, B.N., 1988. Antioxidant defenses and lipid peroxidation in human blood plasma. Proc. Natl. Acad. Sci. U. S. A. 85, 9748-9752.

Halliwell, B., Gutteridge, J.M.C., 1990. The antioxidants of human extracellular fluids. Arch. Biochem. Biophys. 280, 1-8.

Ischiropoulos, H., Al-Mehdi, A.B., 1995. Peroxynitrite-mediated oxidative protein modifications. FEBS Lett. 364, 279-282.

Karikoski, N.P., Patterson-Kane, J.C., Asplin, K.E., McGowan, T.W., McNutt, M., Singer, E.R., McGowan, C.M., 2014. Morphological and cellular changes in secondary epidermal of laminae horses with insulin-induced laminitis. Am. J. Vet. Res. 75, 161-168.

Kim, C.H., 2013. Expression of extracellular superoxide dismutase protein in diabetes. Arch. Plast. Surg. 40, 517-521.

Kyaw, W.O., Uhlig, A., Köller, G., Sack, U., Schusser, G.F., 2008. Free hemoglobin and tumor necrosis factor-alpha in the blood of horses with colic or acute colitis. Berl. Munch. Tierarztl. Wochenschr. 121, 11-12. 
Laskoski, L.M., Valadão, C.A.A., Vasconcelos, R.O., Souza, A.H., Faleiros, R.R., Amorim, R.L., 2010. Morphological abnormalities and apoptosis in lamellar tissue of equines after intestinal obstruction and treatment with hydrocortisone. Arq. Bras. Med. Vet. Zootec. 62, 1331-1339.

Laskoski, L.M., Locatelli-Dittrich, R., Valadão, C.A., Deconto, I., Gonçalves, K.A., Montiani-Ferreira, F., Brum, J.S., de Brito, H.F., de Sousa, R.S., 2015. Systemic leukopenia, evaluation of laminar leukocyte infiltration and laminar lesions in horses with naturally occurring colic syndrome. Res. Vet. Sci. 101, 15-21.

Lima, L.R., Mendes, H.M.F., Magalhães, J.F., Markowicz, L.C., Cavalcanti, C.B., Paes Leme, F.O., Teixeira, M.M., Faleiros, R.R., 2013. Clinical and hematological evaluation of horses subjected to oligofructose-induced laminitis treated or not with a CXCR1/2 antagonist. Pesqui. Vet. Bras. 33, 992-998.

Loftus, J.P., Belknap, J.K., Stankiewicz, K.M., Black, S.J., 2006. Laminar xanthine oxidase: superoxide dismutase and catalase activities in the prodromal stage of black-walnut induced equine laminitis. Equine Vet. J. 39, 48-53.

Loftus, J.P., Black, S.J., Pettigrew, A., Abrahamsen, E.J., Belknap, J.K., 2007. Early laminar events involving endothelial activation in horses with black walnut-induced laminitis. Am. J. Vet. Res. 68, 1205-1211.

Macdonald, J., Galley, H.F., Webster N.R, H.F., 2003. Oxidative stress and gene expression in sepsis. Br. J. Anaesth. 90, 221-232.

Moore, J.N., Vandenplas, M.L., 2014. Is it the systemic inflammatory syndrome or endotoxemia in horses with colic? Vet. Clin. North Am. Equine Pract. 30 337-351.

Noschka, E., Moore, J.N., Peroni, J.F., Lewis, S.J., Morrow, J.D., Robertson, T.P., 2009a. Thromboxane and isoprostanes as inflammatory and vasoactive mediators in black walnut heartwood extract induced equine laminitis. Vet. Immunol. Immunopathol. 129, 200-210.

Noschka, E., Vandenplas, M.L., Hurley, D.J., Moore, J.N., 2009b. Temporal aspects of laminar gene expression during the developmental stages of equine laminitis. Vet. Immunol. Immunopathol. 129, 242-253.

Parsons, C.S., Orsini, J.A., Krafty, R., Capewell, L., Boston, R., 2007. Risk factors for development of acute laminitis in horses during hospitalization: 73 cases (1997-2004). JAVMA 230, 885-889.
Pei, H., Song, X., Peng, C., Tan, Y., Li, Y., Li, X., Ma, S., Wang, O., Huang, R., Yang, D., Li, D., Gao, E., Yang, Y., 2015. TNF- $\alpha$ inhibitor protects against myocardial ischemia/reperfusion injury via Notch1-mediated suppression of oxidative/nitrative stress. Free Radic. Biol. Med. 82, 114-121.

Pollitt, C.C., 1996. Basement membrane pathology: a feature of acute equine laminitis. Equine Vet. J. 28, 38-46.

Seija, M., Baccino, C., Nin, N., Sanchez-Rodrıguez, C., Granados, R., Ferruelo, A., Martınez-Caro, L., Ruız-Cabello, J., Noboa, M.O., Esteban, A., Lorente, J.A., 2012. Role of peroxynitrite in sepsis induced acute kidney injury in an experimental model of sepsis in rats. Shock 38, 403-410.

Szabó, C., Ischiropoulos, H., Radi, R., 2007. Peroxynitrite: biochemistry, pathophysiology and development of therapeutics. Nat. Rev. Drug Discov. 6, 662-680.

Steelman, S.M., Johnson, P., Jackson, A., Schulze, J., Chowdhary, B.P., 2014. Serum metabolomics identifies citrulline as a predictor of adverse outcomes in an equine model of gut-derived sepsis. Physiol. Genomics 46, 339-347.

Toth, F., Frank, N., Chameroy, K.A., Bostont, R.C., 2009. Effects of endotoxaemia and carbohydrate overload on glucose and insulin dynamics and the development of laminitis in horses. Equine Vet. J. 41, 852-860.

Weidinger, A., Kozlov, A.V., 2015. Biological activities of reactive oxygen and nitrogen species: oxidative stress versus signal transduction. Biomolecules 5, $472-484$.

Weiss, D.J., Geor, R.J., Johnston, G., Trent, A.M., 1994. Microvascular thrombosis associated with onset of acute laminitis in ponies. Am. J. Vet. Res. 55, 606-612.

Yin, C., Pettigrew, A., Loftus, J.P., Black, S.J., Belknap, J.K., 2009. Tissue concentrations of 4-HNE in the black walnut extract model of laminitis: indication of oxidant stress in affected laminae. Vet. Immunol. Immunopathol. 129, 211-215.

Zhu, L., Gunn, C., Beckman, J.S., 1992. Bactericidal activity of peroxynitrite. Arch. Biochem. Biophys. 298, 452-457. 